"This document is the Accepted Manuscript version of a Published Work that appeared in final form in Organic Letters, copyright (C) American Chemical Society after peer review and technical editing by the publisher. To access the final edited and published work see". https://pubs.acs.org/doi/10.1021/acs.orglett.8b01957 “

\title{
Development of C2-Symmetric Chiral Bifunctional Triamines: Synthesis and Application in Asymmetric Organocatalysis
}

Santiago Cañellas, Pedro Alonso, and Miquel À. Pericas`*

Institute of Chemical Research of Catalonia (ICIQ), The Barcelona Institute of Science and Technology, Avda. Països Catalans 16, E-43007 Tarragona, Spain

Departament de QuímicaInorganìca i Organìca, Universitat de Barcelona, MartíiFranques`1-11, 08028

Barcelona, Spain

Departament de Química Analítica i Química Orgánica, Universitat Rovira i Virgili, Marcellí Domingo, 1,4300 Tarragona, Spain

\begin{abstract}
Supporting Information
ABSTRACT: The synthesis and application of a newly designed $C_{2}$-symmetric chiral bifunctional triamine family $\left(C_{2}\right.$-CBT $)$ is reported. These enantiopure chiral triamine scaffolds can be accessed in multigram amounts from simple amino acids while avoiding chromatographic purification. As a proof of principle, $C_{2}$-CBT has been studied in the aldol reaction of cyclic ketones with isatins, with the target tertiary alcohols being formed in a highly efficient manner. Catalyst recovery by simple extraction techniques and subsequent reuse has been performed.
\end{abstract}

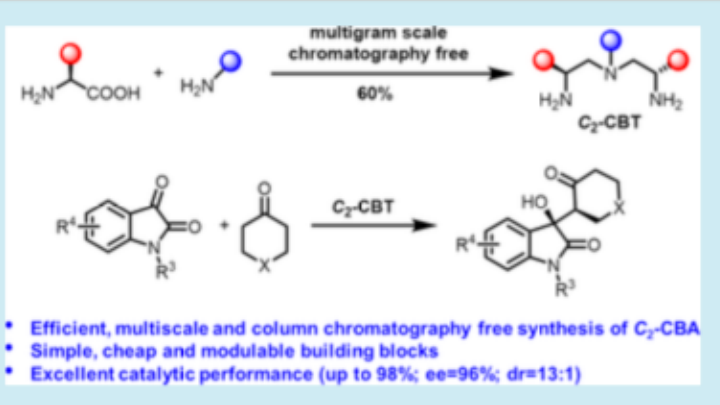

- Simple, cheap and modulable building blocks

Excellent catalytic performance (up to $98 \%$; ee= $96 \%$ dr=13:1)
Asymmetric organocatalysis has attracted a great deal of 1attention over the past two decades, especially dueto the environmentally benign and nontoxic nature, low cost, robustness, operational simplicity, and easy structural modification of the organocatalytic scaffolds.2 In particular, aminocatalysts are a class of organocatalysts based on primary or secondary amines that are able to activate carbonyls, one of the most ubiquitous functional groups in organic chemistry.3,4 This field exploded in 2000, when Barbas, Lerner, List, and MacMillan independently set the concepts of enamine and iminium catalysis. 4 With time, organocatalytic species have gained complexity, approaching enzymes by design and behavior. For instance, the simultaneous activation of at least two functional groups or coupling partners has led to new synthetic transformations that were otherwise impossible or inefficient. To allow further development in this direction, the design of new bior multifunctional catalysts has become a main trend.5,6

In this respect, the presence of a 2-fold symmetry axis in chiral catalytic species usually provides substantial advantages over its nonsymmetric counterpart. Chemically identical active centers of C2-symmetric organocatalysts offer more chances for substrate activation, thus increasing reaction rates and improving selectivities.7 This issue might be especially relevant in amino-catalyzed reactions due to the typically long reaction times.

Taking this into account, and inspired by the performance of chiral vicinal diamines,6a,c-e we envisioned that usually inefficient aminocatalyzed reactions could be ameliorated by the use of a newly designed $\mathrm{C} 2$-symmetric chiral bifunctional organocatalyst type (Figure 1c).

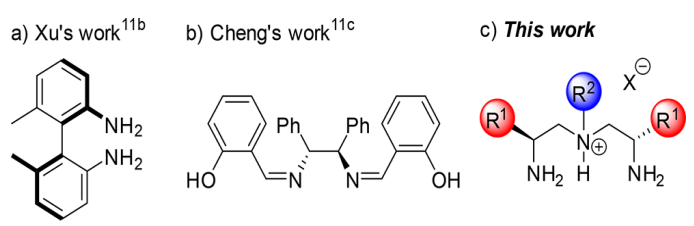

Figure 1. C2-symmetric organocatalysts for aldol reactions.

The aldol condensation of ketones and isatins has emerged as a benchmark reaction within the field of organocatalysis since its first report in 2006 by the group of Tomasini. 8 It is noteworthy that this transformation provides access to enantioenriched compounds possessing a 3hydroxy-2-oxin- dole skeleton, a structural motif that is present in a plethora of natural products and drug candidates with relevant pharmaco- logical properties.9

From a synthetic point of view, one of the main challenges associated with the preparation of this family of compounds is the incorporation of an alkyl chain at the C3position, since controlling the configuration of this quaternary center has proven not to be trivial.10 Nevertheless, great improvements have been achieved in this task through catalyst design, as remarkable degrees of stereocontrol have been reported by the groups of Zhao, Xu, Cheng, and Ishimaru.11 While the groups of Xu and Cheng have already reported the use of C2- symmetric catalysts for the aldol reaction of isatins and ketones (Figure 1), further improvements are yet to be expected. For instance, the group of Xu (Figure 1, a) only reported one example of this transformation, and the conditions described by the group of Cheng (Figure 1, b) required the use of the cyclic ketone as a solvent of the reaction.

Herein, we report the synthesis of a new $\mathrm{C}_{2}$ symmetric chiral aminocatalyst type (Figure 1, c) that 
shows enhanced activity and improved performance in the selected benchmark transformation when compared to typically used amino- catalysts.

For the synthesis of the target chiral triamines, we focused our efforts on the use of cheap and widely available building blocks, the feasibility on multigram scale and the avoidance of column-chromatography separations. The key synthetic step to this end was the double ring-opening of a chiral, $\mathrm{N}$-protected aziridine by a primary amine. The N-protected aziridine, in turn, would be prepared from abundant, enantiopure $\alpha$-amino acids (Scheme 1).

Scheme 1. Synthesis of Organocatalysts I-III

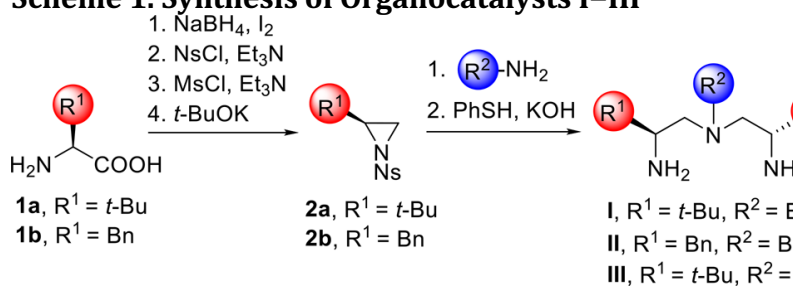

The use of a Boc protecting/activating group of the aziridine moiety in combination with aprotic solvents for the key ring- opening step was initially tested but led to product mixtures due to a very slow second aziridine ring opening. Alternatively, the use of a more efficient activator, such as the nosyl group, and methanol as the solvent allowed

the two consecutive aziridine ring opening steps to be performed in a highly efficient manner. The synthetic approach summarized in Scheme 1 allows the facile structure modification of both the central tertiary amine $\left(\mathrm{R}^{2}\right.$, arising from the primary amine nucleophile) and the bulky $\mathrm{R}^{1}$ group (from the chiral $\alpha$-amino acid) designed to be responsible for enantiodiscrimination. All synthetic steps in the optimized route are simple and highyielding. As we will discuss later, we have developed a chromatography-free, multigram synthesis of the triamines based on this route.

We next explored the catalytic activity of these $\mathrm{C}_{2}$ symmetric triamines using the benchmark aldol reaction of cyclo- hexanones and isatins. For this purpose, we compared the results obtained with catalysts I-III with those obtained with other aminocatalysts typically employed in the same process. Thus, under the conditions summarized in Table 1, the aldol condensation between 1-methylisatin $3 a$ and cyclohexanone 4 a was studied.

Among the new class of $\mathrm{C}_{2}$-symmetric triamine catalysts synthesized, I performed substantially better than II and III (Table 1, entries 1-3). With I, the reaction smoothly proceeded to afford $5 \mathrm{a}$ in $80 \%$ yield as a 13.0:1 mixture of diastereoisomers, the major one with excellent ee (90\%). On the other hand, catalysts II and III performed less efficiently (Table 1, entries 2 and 3). We then compared our best result (Table 1, entry 1) with those obtained with other well-known primary and secondary aminocatalysts. Interestingly, when a nonsymmetric analogue (Luo's catalyst $\mathrm{IV}^{6 \mathrm{C}-\mathrm{e}}$ ) was employed under the same reaction conditions, the same yield was
Table 1. Catalyst Screening

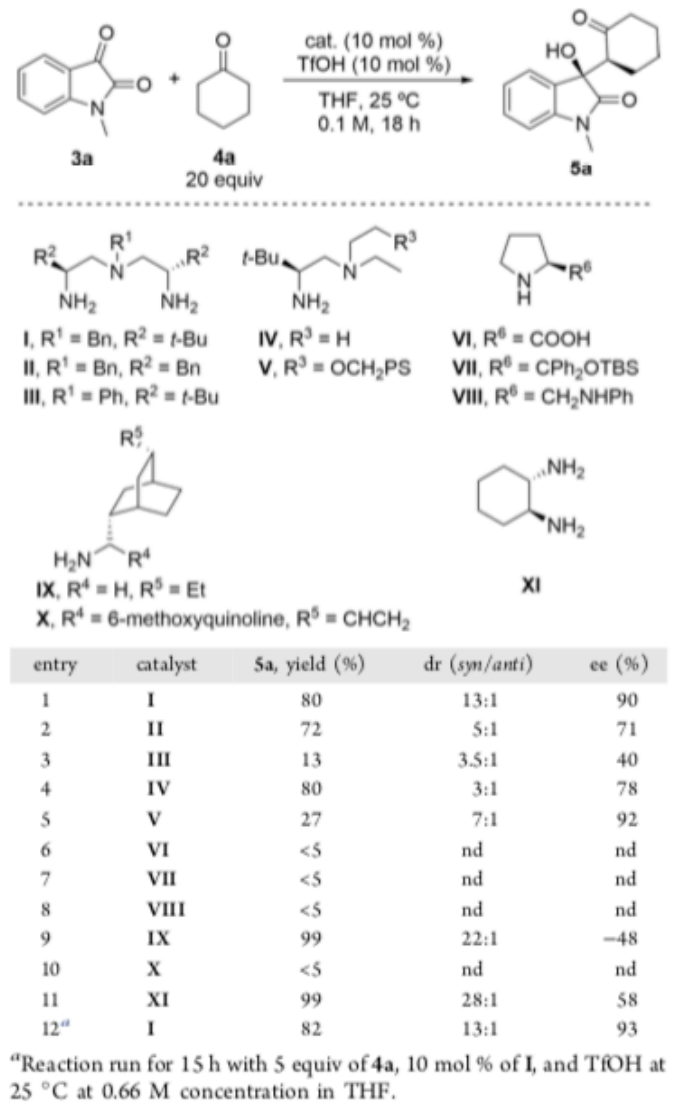

observed for product 3a, while the diastereoselectivity and enantioselectivity of the transformation were significantly lower (Table 1, entry 4). Polystyrenesupported derivative V6a was able to afford a higher enantiomeric excess (92\%) while achieving an acceptable diastereomeric ratio (7:1). However, a much lower catalytic activity was observed (Table 1, entry 5). Very high activities were recorded when diamines IX and $\mathrm{XI}$ were used as catalysts. In these cases, aldol adduct $5 \mathrm{a}$ was isolated in high yield and excellent diastereoselectivity, but only moderate enantioselectivities were achieved (Table 1, entries 9 and 11).

The use of proline, the Jørgensen-Hayashi catalyst, or a similar diamine VI, VII, or VIII resulted in almost complete recovery of the starting material, an outcome that highlights the importance of primary amines for the activation of ketones in the aldol reaction (Table 1 , entries 6-8). Finally, after further experimentation, we identified the best conditions to carry out this transformation as those summarized in entry 12 of Table 1 , where 5 a could be isolated in $82 \%$ yield as a 13.0:1 mixture of diastereoisomers (syn/anti) and 93\% enantiomeric excess for the major diastereoisomer using the C2-CBT catalyst I.12

Among several reaction parameters, we studied the influence of the ratio I/TfOH to the catalytic performance. The best 
balance between the yield and the enantiomeric excess was found with equimolar ratio of the catalyst I and $\mathrm{TfOH}$. This fact suggests that both primary amines are involved in the generation of reactive enamine intermediates. On the other hand, the in situ generated ammonium triflate salt from the central tertiary amine plays a crucial role on the activation of the isatin. Nonetheless, we cannot rule out the possibility of an additional role of the second primary amine as a hydrogen- bond donor. ${ }^{12}$

Having identified the optimized conditions to carry out the aldol reaction between 1-methylisatin and cyclohexanone, the applicability of the method was tested by studying the scope of the reaction. Therefore, a set of isatins with different substitution patterns 3 was reacted with a series of cyclic ketones 4 , leading to the formation of aldols $5 \mathrm{a}-\mathrm{r}$. The results of this study are shown in Scheme 2. Remarkably, the efficiency of the $\mathrm{C}_{2}$ CBT aminocatalyst I was demonstrated since complete conversion of the starting materials was generally observed after $15 \mathrm{~h}$ of reaction at $25^{\circ} \mathrm{C}$ while using a 5fold excess of the corresponding ketone. As the results gathered in Scheme 2 show, substitution in the nitrogen atom does not affect the diastereo- and

Scheme 2. Scope and Limitations of the Reaction ${ }^{a}$
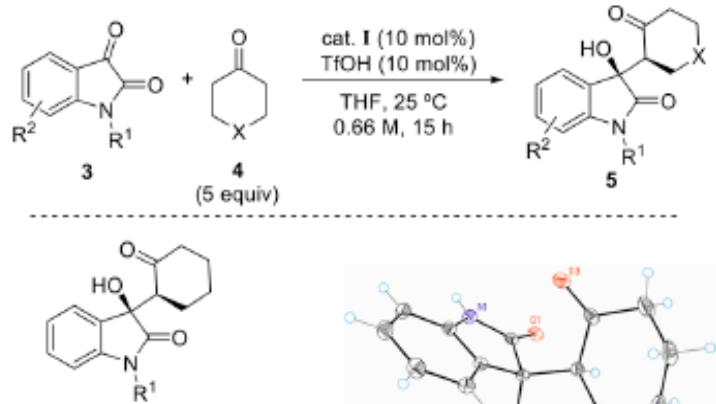

5a, $R^{1}=\operatorname{Me}(82 \%, d r=13: 1$, ee $=93 \%)$

$5 b, R^{1}=H(98 \%, d r=8: 1, e \theta=93 \%)$

5c, $R^{1}=\operatorname{Bn}(92 \%, d r=9: 1, e e=96 \%)$

5d, $R^{1}=\operatorname{Boc}(78 \%, d r=9: 1, e e=94 \%)$

$5 e, R^{1}=\operatorname{Ph}(95 \%, d r=8: 1, e e=84 \%)$

5f, $R^{1}=$ allyl $(91 \%, d r=11: 1, \theta \theta=87 \%)$

5g, $R^{1}=$ propargyl $(96 \%, d r=9: 1, e \theta=94 \%)$

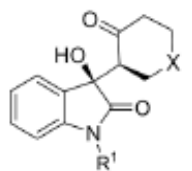

' 1

$5 \mathrm{~m}, \mathrm{X}=\mathrm{S}, \mathrm{R}^{1}=\mathrm{Me}(81 \%, \mathrm{dr}=6: 1, e e=91 \%)$

5n, $X=S, R^{1}=H(80 \%, d r=13: 1,6 \theta=93 \%)$

5o, $X=O, R^{1}=H(82 \%, d r=4: 1,66=63 \%)$

5p, $\mathrm{X}=\mathrm{CMe}_{2}, \mathrm{R}^{1}=\mathrm{H}(92 \%, \mathrm{dr}=10: 1, e e=75 \%)$

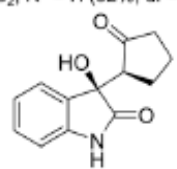

${ }^{[b]} \mathbf{5 r}(71 \%, d r=1.3: 1, e e=66 \%)$
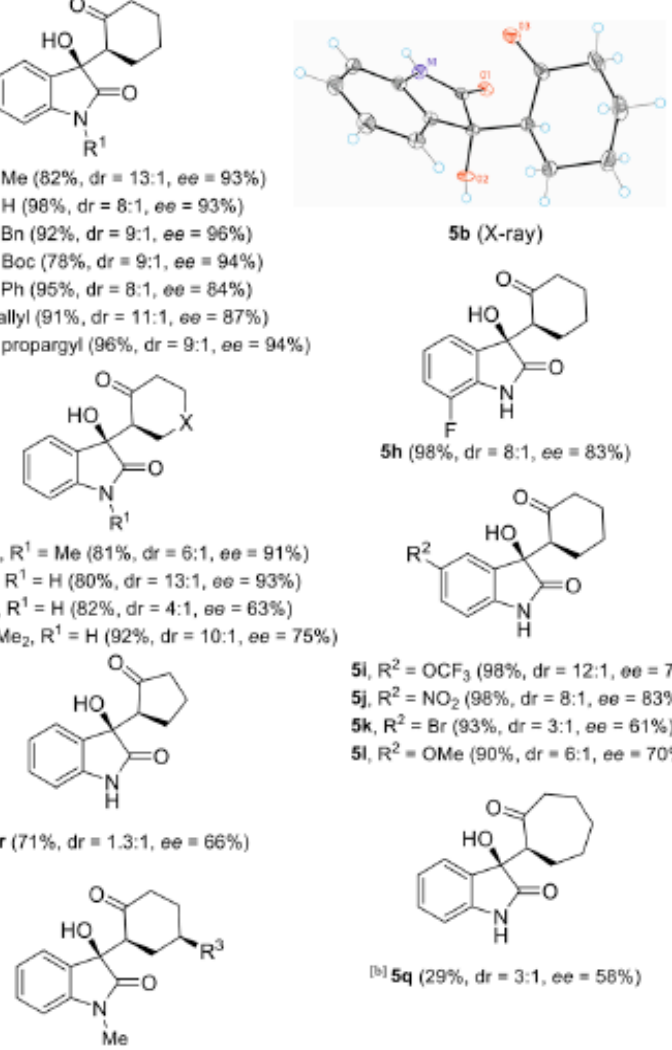

$5 b(X-r a y)$

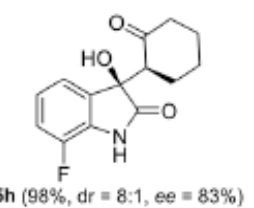

$5 \mathrm{~h}(98 \%, \mathrm{dr}=8: 1, \mathrm{ee}=83 \%)$

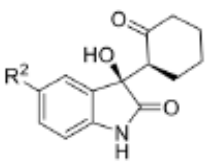

$5 i, R^{2}=\mathrm{OCF}_{3}(98 \%, \mathrm{dr}=12: 1, e e=77 \%)$ 5j. $\mathrm{R}^{2}=\mathrm{NO}_{2}(98 \%, \mathrm{dr}=8: 1, e \theta=83 \%)$ $5 k, R^{2}=\operatorname{Br}(93 \%, d r=3: 1, e \theta=61 \%)$ $51, R^{2}=$ OMe $(90 \%$, dr $=6: 1$, ee $=70 \%)$

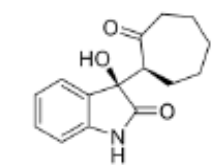

[B] $5 q(29 \%, d r=3: 1, e e=5 B \%)$

5s, $R^{3}=\mathrm{Me}_{\theta}(94 \%, \mathrm{dr}=6: 1: 1, \theta e=82 \%)$

St, $R^{3}=t-B u(88 \%, d r=10: 1: 1$, ee $=84 \%)$

${ }^{a}$ General reaction conditions: 3 ( $\left.0.181 \mathrm{mmol}\right), 4$ (5 equiv), I ( $10 \mathrm{~mol}$ $\%)$, TfOH (10 mol \%), THF (0.66 M), $25^{\circ} \mathrm{C}, 15 \mathrm{~h} .{ }^{b}$ Reaction time was extended to $36 \mathrm{~h}$.

enantioselectivity of the process, since up to seven different $\mathrm{N}$-substituted adducts were synthesized with excellent results $(5 \mathrm{a}-\mathrm{g})$. The relative configuration of the adducts was unambiguously assigned by X-ray singlecrystal analysis of $5 \mathrm{~b}$ with the assumption of a similar stereochemical course, as is present in the other studied cases. $^{13}$

The induction of chirality proved to be more challenging when isatins bearing functionality in the aromatic ring were used, regardless of the electronic properties of the substituent. Thus, compounds $5 \mathrm{~h}-\mathrm{l}$ were obtained with slightly lower enantioselectivities (ee $=61-83 \%$ ), while yields and diastereoisomeric ratios were generally very high. These results are in good agreement with other studies reported in the literature and place I among the best catalysts for this reaction. $10 \mathrm{~b}, \mathrm{f}, \mathrm{g}$ Finally, other cyclic ketones were tested in order to further enlarge the scope of the transformation. In this case, when tetrahydro-4Hthiopyran-4-one was used for the reaction, excellent results were obtained since compounds $5 \mathrm{~m}, \mathrm{n}$ were isolated in high yields and excellent diastereo- and enantioselectivities. Nevertheless, when other ketone deriva- tives were employed such as tetrahydro- $4 \mathrm{H}$ pyran-4-one and 4,4-dimethylcyclohexanone, adducts $5 o$ and $5 p$ were synthe- sized in excellent yields, albeit with moderate to good enantiomeric excesses. In addition, cyclopentanone and cycloheptanone gave their corresponding aldol products $3 \mathrm{q}$ and $3 \mathrm{r}$ with poor diasteroselectivity under these reaction conditions, a result that is in good agreement with other reported catalysts for this transformation. 10f,g Finally, the desymmetrization of 4-substituted cyclohexanones was per-formed, exerting remarkable levels of stereocontrol. Thus, adducts $5 \mathrm{~s}$ and $5 \mathrm{t}$ were isolated with good diastereoselectivities ( $\mathrm{dr}=6: 1: 1$ for $5 \mathrm{~s}$ and 10:1:1 for $5 \mathrm{t}$ ) and enantioselectivities ( $\mathrm{ee}=82-84 \%$ ).

As already mentioned, given the straightforward nature of the preparation of I and its optimal catalytic performance, effort was devoted to the development of a practical synthesis for this $\mathrm{C}_{2}$-symmetric chiral triamine. Taking into account the clean nature of the reactions involved in the preparation of I, we concentrated on the use of simple purification procedures (extraction, precipitation, or crystallization) on a multigram scale (Scheme 3). ${ }^{12}$ In this manner, an overall 60\% yield could be recorded in the six-step sequence from tert-leucine, and catalyst I could be characterized by single-crystal Xray analysis.

Inspired by the last step of the catalyst synthesis (where the catalyst is extracted to the aqueous phase under acidic conditions and extracted back to the organic phase under basic conditions), we envisioned that the catalyst could be easily recovered at the end of the enantioselective trans- formation by using simple extraction techniques. This would make possible overcoming one of the most important limitations associated with the use of homogeneous catalysts, that is, the possibility of efficient recovery and reuse.

To test this possibility, isatin $3 \mathrm{~b}$ was reacted with cyclohexanone 4 a on a $5 \mathrm{mmol}$ scale under the optimized reaction conditions (Scheme 4). Once the starting material was consumed, aqueous $\mathrm{HCl}$ was added, and the aldol product $5 \mathrm{~b}$ was extracted in $\mathrm{CH}_{2} \mathrm{Cl}_{2}$ with excellent results $(85 \%$ yield, ee $=93.7 \%$ and $d r=12.4: 1)$. Then the aqueous phase was treated with aqueous $\mathrm{NaOH}$ and the catalyst was extracted in $\mathrm{CH}_{2} \mathrm{Cl}_{2} \quad(75 \%$ recovery, analytically pure). This recovered catalyst was 
Scheme 3. Multigram Scale and Column Chromatography Free Synthesis of $\mathrm{C}_{2}$-Symmetric Chiral Bifunctional Triamine I

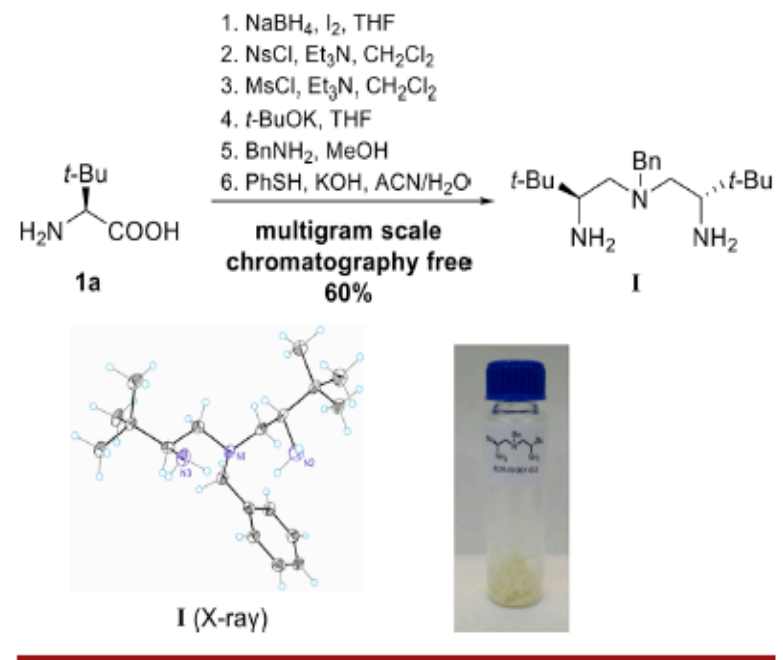

Scheme 4. Scale-up Reaction, Recovery, and Reuse of $C_{2}$ Symmetric Chiral Bifunctional Triamine I

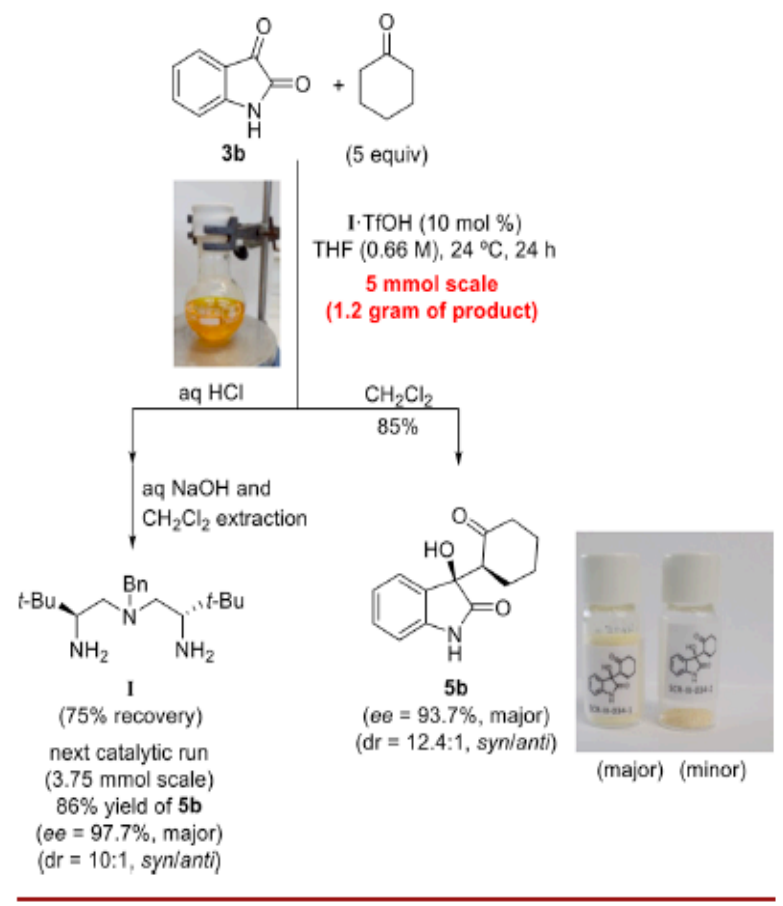

reused in a new catalytic cycle (3.75 mmol of $3 b$ ) showing the same catalytic activity as the fresh batch ( $86 \%$ yield, ee $=97.7 \%$ and $d r=10: 1)$.

In summary, we have synthesized a new class of C2symmetric chiral bifunctional triamines (C2-CBT) from cheap and widely available chiral $\alpha$-amino acids and primary amines. These organocatalysts showed an excellent performance in the enantioselective aldol addition of cyclic ketones to isatins (up to $98 \%$ yield, ee $=96 \%, \mathrm{dr}=13: 1$ ). The catalyst of choice was synthesized on a multigram scale with high overall yield and using operationally simple techniques (avoiding column chromatography purifications). Moreover, the chiral catalyst was recovered after the enantioselective reaction by extraction techniques and was reused in a new catalytic cycle. We are currently focused on the use of this C2-CBT scaffold and its derivatives as a ligand in metal-catalyzed asymmetric transformations.

\section{ASSOCIATED CONTENT \\ Supporting Information}

The Supporting Information is available free of charge on the ACS Publications website at DOI: 10.1021/acs.orglett.8b01957.

Experimental procedures and spectral data (PDF)

\section{Accession Codes}

CCDC 1851132-1851133 contain the supplementary crys- tallographic data for this paper. These data can be obtained free of charge via www.ccdc.cam.ac.uk/data_request/cif, or by emailing data_request@ccdc.cam.ac.uk, or by contacting The Cambridge Crystallographic Data Centre, 12 Union Road, Cambridge CB2 IEZ, UK; FAX:+44 1223336033.

\section{AUTHOR INFORMATION \\ Corresponding Author \\ *E-mail: mapericas@iciq.es. ORCID \\ Santiago Cañellas: 0000-0002-8700-4615 \\ Miquel A. Pericas̀:0000-0003-0195-8846 \\ Notes}

The autor declare no competing financial interest.

\section{ACKNOWLEDGMENTS}

Financial support from the MINECO (Grant No. CTQ2015- 69136-R (AEI/MINECO/FEDER, UE)) and CERCA Pro- gramme/Generalitat de Catalunya and DEC Generalitat de Catalunya (Grant No. 2014SGR827) is gratefully acknowl- edged. We also thank the MINECO for support through the Severo Ochoa Excellence Accreditation 2014-2018 (SEV- 2013-0319). S.C. thanks the AEI/MINECO for a Severo Ochoa FPI fellowship (BES2015-072152). We are grateful to the ICIQ X-ray diffraction unit for the single-crystal X-ray analyses of I and $5 \mathrm{~b}$ and Dr. Ayats (Institute of Chemical Research of Catalonia) for his contribution in the preliminary stages.

\section{PREFERENCES}

(1) (a) List, B. Chem. Rev. 2007, 107, 5413-5415. (b) MacMillan, D. W. C. Nature 2008, 455, 304-308.

(2) Anebouselvy, K.; Ramachary, D. B.; Kumar, I. Dienamine Catalysis for Organic Synthesis; The Royal Society of Chemistry, 2018. (3) (a) Dalko, P. I. Enantioselective Organocatalysis; Wiley-VCH: Weinheim, 2007. (b) Zhang, L.; Fu, N.; Luo, S. Acc. Chem. Res. 2015, 48, 986-997.

(4) (a) List, B.; Lerner, R. A.; Barbas, C. F., III. J. Am. Chem. Soc. 2000, 122, 2395-2396. (b) Ahrendt, K. A.; Borths, C. J.; MacMillan, D. W. C. J. Am. Chem. Soc. 2000, 122, 4243-4244. (c) Erkkila;, A.; Majander, I.; Pihko, P. M. Chem. Rev. 2007, 107, 5416-5470. (d) Mukherjee, S.; Yang, J. W.; Hoffmann, S.; List, B. Chem. Rev. 2007, 107, 5471-5569.

(5) For selected early examples on bifunctional catalysts, see: (a) Hamashima, Y.; Sawada, D.; Kanai, M.; Shibasaki, M. J. Am. Chem. Soc. 1999, 121, 2641-2642. (b) Takamura, M.; Funabashi, K.; Kanai, M.; Shibasaki, M. J. Am. Chem. Soc. 2001, 123, 6801-6808. (c) Shibasaki, M.; Yoshikawa, $N$. Chem. Rev. 2002, 102, 2187- 2210. (d) Li, H.; Wang, Y.; Tang, L.; Deng, L. J. Am. Chem. Soc. 2004, 126, 9906-9907. (e) Fuerst, D. E.; Jacobsen, E. N. J. Am. Chem. Soc. 2005, 127, 8964-8965. (f) Li, H.; Wang, Y.; Tang, L.; Wu, F.; Liu, X.; 
Guo, C.; Foxman, B. M.; Deng, L. Angew. Chem., Int. Ed. 2005, 44, 105-108. (g) Zuend, S. J.; Jacobsen, E. N. J. Am. Chem. Soc. 2007, 129, 15872-15883. For the preparation of $N, N^{\prime}-$ bis(tosyl), C2- symmetric triamines and their use as ligands in the Ti-mediated asymmetric ethylation of benzaldehyde, see: (h) Cernerud, M.; Skrinning, A.; Beŕgere, I.; Moberg, C. Tetrahedron: Asymmetry 1997, 8, 3437-3441. (i) Lake, F.; Moberg, C. Tetrahedron: Asymmetry 2001, 12, 755-760. (j) Lake, F.; Moberg, C. Eur. J. Org. Chem. 2002, 2002, 3179-3188. (6) For recent examples on bifunctional organocatalysis, see: (a)Cañellas,S.; Ayats,C.;Henseler,A.H.;Pericas̀,M. ACS Catal. 2017, 7, 1383-1391. (b) Jiménez, E. I.; Vallejo Narvaéz, W. E.; Rocha-Rinza, T.; Hernańdez-Rodríguez, M. Catal. Sci. Technol.2017, 7, 4470-4477. (c) You, Y.; Zhang, L.; Cui, L.; Mi, X.; Luo, S. Angew. Chem., Int. Ed. 2017, 56, 13814-13818. (d) Zhu, L.; Zhang, L.; Luo, S. Angew. Chem., Int. Ed. 2018, 57, 2253-2258. (e) Cui, L.; You, Y.; Mi, X.; Luo, S. J. Org. Chem. 2018, 83, 4250-4256. (f) Matador, E.; Retamosa, M.; Monge,D.; Iglesias-Sigüenza, J.;Fernández, R.; Lassaletta, J. M. Chem. - Eur. J. 2018, 24, 6854-6860.

(7) For a review on $\mathrm{C}_{2}$-symmetric diamines as asymmetric organocatalysts, see: Zlotin, S. G.; Kochetkov, S. V. Russ. Chem. Rev. 2015, 84, 1077-1099 and references cited therein.

(8) Luppi, G.; Cozzi, P. G.; Monari, M.; Kaptein, B.; Broxterman, Q. B.; Tomasini, C. J. Org. Chem. 2005, 70, 7418-7421.

(9) (a) Popp, F. D.; Parson, R.; Donigan, B. E. J. Heterocycl. Chem. 1980, 17, 1329-1330. (b) Monde, K.; Sasaki, K.; Shirata, A.; Takasugi, M. Phytochemistry 1991, 30, 2915-2917. (c) Rasmussen, H. B.; MacLeod, J. K. J. Nat. Prod. 1997, 60, 1152-1154. (d) Kohno, J.; Koguchi, Y.; Nishio, M.; Nakao, K.; Kuroda, M.; Shimizu, R.; Ohnuki, T.; Komatsubara, S. J. Org. Chem. 2000, 65, 990-995. (e) Tokunaga, T.; Hume, W. E.; Umezome, T.; Okazaki, K.; Ueki, Y.; Kumagai, K.; Hourai, S.; Nagamine, J.; Seki, H.; Taiji, M.; Noguchi, H.; Nagata, R. J. Med. Chem. 2001, 44, 4641-4649. (f) Suchy', M.; Kutschy, P.; Monde, K.; Goto, H.; Harada, N.; Takasugi, M.; Dzurilla, M.; Balentova, E. J. Org. Chem. 2001, 66, 3940-3947. (g) Hibino, S.; Choshi, T. Nat. Prod. Rep. 2001, 18,66-87. (h) Frećhard, A.; Fabre, N.; Peán, C.; Montaut, S.; Fauvel, M.-T.; Rollin, P.; Fouraste, I. Tetrahedron Lett. 2001, 42, 9015-9017. (i) Lin, S.; Danishefsky, S. J. Angew. Chem., Int. Ed. 2002, 41, 512-515. (j) Hewawasam, P.; Erway, M.; Moon, S. L.; Knipe, J.; Weiner, H.; Boissard, C. G.; Post-Munson, D. J.; Gao, Q.; Huang, S.; Gribkoff, V. K.; Meanwell, N. A. J. Med. Chem. 2002, 45, 1487-1499. (k) Kawasaki, T.; Nagaoka, M.; Satoh, T.; Okamoto, A.; Ukon, R.; Ogawa, A. Tetrahedron 2004, 60, 3493- 3503.

(10) (a) Shen, C.; Shen, F.; Xia, H.; Zhang, P.; Chen, X. Tetrahedron: Asymmetry 2011, 22, 708-712. (b) Liu, Y.; Gao, P.; Wang, J.; Sun, Q.; Ge, Z.; Li, R. Synlett 2012, 23, 1031-1034. (c) Hernańdez, J.G.; García-Loṕez, V.; Juaristi, E. Tetrahedron 2012, 68, 92-97. (d) Guo, Q.; Zhao, J. C.-G. Tetrahedron Lett. 2012, 53, 1768-1771. (e) Zhang, F.; Li, C.; Qi, C. Tetrahedron: Asymmetry 2013, 24, 380-388. (f) Wang, J.; Liu, Q.; Hao, Q.; Sun, Y.; Luo, Y.; Yang, H. Chirality 2015, 27, 314-319. (g) Ogasawara, A.; Reddy, U. V. S.; Seki, C.; Okuyama, Y.; Uwai, K.; Tokiwa, M.; Takeshita, M.; Nakano, H. Tetrahedron: Asymmetry 2016, 27, 1062-1068. (h) Cao, Z.-Y.; Zhou, F.; Zhou, J. Acc. Chem. Res. 2018, 51, 1443-1454.

(11) (a) Guo, Q.; Bhanushali, M.; Zhao, C.-G. Angew. Chem., Int. Ed. 2010, 49, 9460-9464. (b) Deng, Y.; Liu, L.; Sarkisian, R. G.; Wheeler, K.; Wang, H.; Xu, Z. Angew. Chem., Int. Ed. 2013, 52, 3663- 3667. (c) Mao, Z.; Zhu, X.; Lin, A.; Li, W.; Shi, Y.; Mao, H.; Zhu, C.; Cheng, Y. Adv. Synth. Catal. 2013, 355, 2029-2036. (d) Tanimura, Y.; Yasunaga, K.; Ishimaru, K. Eur. J. Org. Chem. 2013, 2013, 6535- 6539.

(12) See the Supporting Information for further details.

(13) The absolute configuration was assigned by comparing the HPLC traces with reported data. 